\title{
Práticas pedagógicas em classe multisseriada na educação do campo
}

\author{
Pedagogical practices in multiseriate class in rural education \\ Suelem Cardoso Miranda Rodrigues \\ Sandra Mara Santana Rocha \\ Rita de Cassia Cristofoleti
}

\begin{abstract}
Resumo: O presente trabalho, que é fruto de uma dissertação de mestrado, busca contextualizar o plano de estudo, enquanto elemento pedagógico da Educação do Campo. A pesquisa aconteceu em uma classe multisseriada localizada na zona rural do município de São Mateus-Espírito Santo. O objetivo da pesquisa foi analisar se a Educação Ambiental, como tema transversal, pode ser entrelaçada aos processos de alfabetização dos estudantes de 4 a 8 anos de idade e nos temas geradores propostos pelo currículo das escolas multisseriadas do campo. A metodologia utilizada foi a pesquisa-ação de abordagem qualitativa em que foram utilizadas a observação participante, assim como atividades de intervenção pedagógica para desenvolver uma sequência didática no ensino de Educação Ambiental. Os resultados encontrados revelam as possibilidades de inserção da Educação Ambiental no cotidiano escolar a partir dos temas geradores das escolas do campo, ressaltando a importância desse trabalho como forma de dialogar com o contexto social e ambiental de meninos e meninas do campo, além de possibilitar práticas de alfabetização significativas e contextualizadas acompanhadas de práticas situadas de letramento. Neste sentido, o presente artigo abordará uma parte da pesquisa realizada evidenciando uma prática significativa e contextualizada a partir do plano de estudo que é um elemento pedagógico das escolas do campo.
\end{abstract}

Palavras-chave: Plano de estudo. Elemento pedagógico. Classe multisseriada. Educação do campo.

Abstract: The present work, which is the result of a master's thesis, seeks to contextualize the study plan, as a pedagogical element of Rural Education. The research took place in a multiseriate class located in the rural area of the municipality of São Mateus-Espírito Santo. The objective of the research was to analyze whether Environmental Education, as a cross-cutting theme, can be intertwined with the literacy processes of students from 4 to 8 years of age and in the generating themes proposed by the curriculum of multiserial schools in the field. The methodology used was action research with a qualitative approach in which participant observation was used, as well as pedagogical intervention activities to develop a didactic sequence in the teaching of Environmental Education. The results found reveal the possibilities of insertion of Environmental Education in the school daily life from the themes that generate rural schools, emphasizing the importance of this work as a way of dialoguing with the social and environmental context of rural boys and girls, in addition to enabling practices meaningful and contextualized literacy courses accompanied by situated literacy practices. In this sense, this article will address a part of the research carried out showing a meaningful and contextualized practice based on the study plan, which is a pedagogical element of rural schools.

Keywords: Study plan. Pedagogical element. Multiseriate class. Rural education. 


\section{Introdução}

As classes multisseriadas fazem parte do processo de constituição da Educação do Campo. As salas multisseriadas, têm como principal característica a junção de alunos de diferentes idades, diferentes séries e diferentes níveis de aprendizagem, em uma mesma classe onde a responsabilidade de ensino é de, na maioria das vezes, apenas um professor. Sabemos, ainda, que por muito tempo as atribuições do professor das escolas multisseriadas foram as mais variadas. Nelas deviam exercer a função de diretor, de pedagogo, de secretário escolar, recepcionista e outras, juntamente com a função docente. Entretanto, essa realidade vem mudando, e compreendemos que a partir da história encontramos pistas que nos desafiam a produzir outros discursos acerca da escola multisseriada. Nesse contexto, esse artigo evidencia práticas pedagógicas relevantes desenvolvidas em uma classe multisseriada, ressaltando a importância da mesma como uma alternativa para não afastar as crianças de sua realidade propiciando, uma formação escolar adequada às condições das crianças do campo.

É importante ressaltar que este artigo originou-se de uma pesquisa de mestrado financiada pela FAPES e CAPES, cujo objetivo foi analisar se a Educação Ambiental, como tema transversal, pode ser entrelaçada aos processos de alfabetização dos estudantes de 4 a 8 anos de idade e nos temas geradores propostos pelo currículo das escolas multisseriadas do campo. A metodologia utilizada foi a pesquisa-ação de abordagem qualitativa, tendo em vista que a pesquisadora não foi uma mera observadora dos acontecimentos, mas interagiu e trabalhou juntamente com os atores envolvidos nesta pesquisa buscando elucidar a realidade em que se inserem. Gerenciando mudanças necessárias, ou seja, realizando ajustes entre as novas informações e acontecimentos na busca por soluções em situações reais (GIL, 2014).

A produção de dados foi realizada por meio de observação participante, assim como, atividades de intervenção pedagógica para desenvolver uma sequência didática no ensino de Educação Ambiental. Como instrumentos de coleta de dados foram utilizados a observação participante, rodas de conversas, relatos orais, o registro das falas com anotações em diários de campo e 
gravações das rodas de conversa realizadas com as crianças em áudio, produção textual, relatos escritos, visitas de estudo, fotografias, filmagens, desenhos, ilustrações e demais atividades realizadas pelos estudantes para análise dos dados.

A pesquisa foi realizada em uma classe multisseriada localizada na zona

rural do município de São Mateus-Espírito Santo. O Plano de estudo ${ }^{1}$ foi um elemento pedagógico que esteve presente durante a pesquisa realizada, desenvolvendo ações que aperfeiçoaram o fazer pedagógico por meio da teoria e prática, garantindo a realidade da comunidade no cotidiano escolar. Por isso, esse artigo abordará uma parte da pesquisa realizada, o qual será evidenciado o "fazer" pedagógico por meio do Plano de estudo no contexto da escola pesquisada.

\section{Contextualizando a Educação do Campo}

O movimento inicial da Educação do Campo representa uma articulação política dos movimentos sociais do campo em resposta à precária educação ofertada nas escolas do meio rural. Ao mesmo tempo, tem sido um movimento de reflexão pedagógica das experiências camponesas, estabelecendo assim, uma luta por políticas públicas de educação no e do campo e mobilização popular em torno de outro projeto de desenvolvimento (CALDART, 2004). Pois a Educação do Campo vincula-se à luta pela Terra e aos movimentos sociais, contribuindo para a construção de um projeto educativo que prioriza e respeita o ser humano em suas especificidades. Assim, a proposta de Educação do Campo

\footnotetext{
10 Plano de Estudo, enquanto elemento pedagógico, busca problematizar a realidade concreta dos estudantes, por meio da investigação da realidade, na qual os estudantes expressam os seus saberes prévios, bem como trazem as reflexões feitas na família. Diante disso, os educadores vão mediando, na escola, um processo de colocação em comum e síntese dessas realidades, a fim de, juntamente com os estudantes, elencar situações que necessitam de aprofundamento científico, por isso o Plano de Estudo, é desenvolvido possibilitando o movimento entre o saber prévio dos estudantes e o saber que vai ser reelaborado durante 0 processo de produção de conhecimento. A dinâmica do Plano de Estudo tem como finalidade proporcionar a investigação da realidade concreta, a qual se manifesta nas colocações dos saberes prévios dos estudantes. Estes, por sua vez, são sistematizados e dão base ao trabalho a ser desenvolvido pelas disciplinas, tendo em vista que os conhecimentos científicos contribuem na tomada de consciência dos estudantes sobre suas realidades (RACEFFAES, 2010; ALMEIDA, 2018).
} 
se contrapõe ao modelo de desenvolvimento capitalista para o campo expresso no modelo do agronegócio.

Com o desenvolvimento do capitalismo no campo e seu atual modelo de produção, são produzidas tecnologias para ampliar cada vez mais o agronegócio, e em consequência disso a produção familiar perde espaço. De acordo com Scarabeli (2014, p. 84), "[...] trata-se de uma concepção sobre um determinado modelo de produção que serve ao capital e, contraditoriamente, explora e destrói o meio ambiente e a força de trabalho". Segundo Lima e Fernandes (2018), este modo de produção dominante, com a produção agrícola e pecuária intensiva, baseada na monocultura, tem provocado o aumento da marginalidade e da criminalidade, além de ser, em parte, responsável pela criação e aprofundamento da crise econômica, ambiental e social que assola a humanidade.

Para Camacho (2009), o capitalismo em sua lógica perversa tem como principais características o consumismo desenfreado e a exploração descomedida da natureza. Exploração da natureza combinada com a exploração das pessoas, pois este processo gera mais-valia, permitindo a acumulação do capital. Por isso, esse processo de desenvolvimento capitalista no campo é responsável pela exclusão e marginalização dos povos, além da destruição da biodiversidade, colocando em risco toda a humanidade.

Nesse contexto, uma Educação do Campo perpassa também por uma política bem definida de agricultura que atenda às especificidades e que possibilite a permanência das pessoas no meio rural. Além de apoio aos que já vivem no campo, é urgente que aconteça a distribuição das terras e aqueles que dela saíram possam retornar tendo acesso a ela. Torna-se necessário recuperar os vínculos entre educação e terra, pois o campo é um espaço de grandes possibilidades. Nele há possibilidades de relação com os seres humanos, com sua própria produção, com o resultado de seu trabalho e com a natureza, que proporciona o seu sustento (MANTOVANELLI, 2013).

Neste sentido, a Educação do Campo se configura não apenas como um projeto de educação que se preocupa com um ambiente educativo baseado na valorização da cultura camponesa, na dimensão educativa do trabalho, na 
cultura, identidade e história dos povos do campo, mas, também, como um projeto de sociedade que busca uma educação vinculada a um novo modelo de desenvolvimento e de vida, em que a justiça social, o respeito ao meio ambiente e a participação democrática prevaleçam (LIMA; FERNANDES, 2018).

É importante destacar que a Educação do Campo tomou forma pelas lutas dos movimentos sociais camponeses com o apoio de outras organizações sociais e por meio de reivindicações passou a fazer parte das pautas políticas com o governo.

O termo 'Educação do Campo' foi introduzido pela primeira vez no I Encontro Nacional de Educadoras e Educadores da Reforma Agrária - ENERA, realizado em 1997, promovido pelo Movimento dos Trabalhadores Rurais sem Terra - MST, Universidade de Brasília - UNB, Organização das Nações Unidas para a Educação, Ciência e Cultura - UNESCO, Fundo das Nações Unidas para a Infância - UNICEF e Conferência Nacional dos Bispos do Brasil - CNBB (CALDART, 2004).

Em 1998, um ano após o I Enera, aconteceu a I Conferência Nacional Por Uma Educação Básica do Campo, realizada em Luziânia-GO. Neste evento, foram ratificadas as discussões iniciadas no I ENERA e deu início a uma mobilização em favor da educação do campo, fortalecendo a contextualização do diferencial das escolas do campo e reafirmando o direito dos povos do campo, as políticas públicas de educação com respeito às especificidades, em contraposição às políticas compensatórias da educação rural.

A expressão ‘Campo' e não mais 'meio rural', foi ampliada e fortalecida nas discussões dessa conferência como mostra Kolling; Nery; Molina (1998, p. 26),

Utilizar-se-á a expressão campo, e não mais a usual meio rural, com o objetivo de incluir no processo da conferência uma reflexão sobre o sentido atual do trabalho camponês e das lutas sociais e culturais dos grupos que hoje tentam garantir a sobrevivência desse trabalho. Mas quando se discutir a educação do campo se estará tratando da educação que se volta ao conjunto dos trabalhadores e das trabalhadoras do campo, sejam os camponeses, incluindo os quilombolas, sejam as nações indígenas, sejam os diversos tipos de assalariados vinculados à vida e ao trabalho no meio rural. 
Assim, o movimento pela Educação do Campo reflete a luta desses povos por políticas públicas que garantam o direito à educação e uma educação que seja no campo e do campo, como afirma Caldart (2002, p. 18, grifo do autor),

[...] No: o povo tem direito de ser educado no lugar onde vive; Do: o povo tem direito a uma educação pensada desde o seu lugar e com a sua participação, vinculada à sua cultura e às suas necessidades humanas e sociais.

Neste sentido, o movimento "Por uma Educação Básica do Campo" constitui-se com o desafio de construir e contextualizar a Educação do Campo em relação às políticas públicas, aos seus princípios e seu fazer pedagógico.

Em 2004, foi realizada a II Conferência Nacional de Educação do Campo, definindo a ampliação de novos caminhos de luta, sinalizando a construção de um processo histórico da educação, conduzido e organizado pelos sujeitos sociais do território campesino.

Entretanto, apesar dos avanços, muitas das demandas historicamente negadas ainda se mantêm, por isso, nota-se que a valorização das especificidades dos povos do campo permanece como um processo de constante reivindicação. Assim, a prática educativa nas classes multisseriadas faz parte desse processo de constituição da Educação do Campo.

\section{As classes multisseriadas na educação do campo}

As salas e escolas multisseriadas foram se constituindo como uma realidade no campo, primeiro sob responsabilidade do Estado e, posteriormente, assumidas pelo município (JESUS; FOERSTE, 2018). As classes multisseriadas, também conhecidas como unidocentes ou pluridocentes, têm como característica principal a junção de alunos de diferentes idades, diferentes séries e diferentes níveis de aprendizagem, em uma mesma classe onde a responsabilidade de ensino é de, na maioria das vezes, apenas um professor. Essas classes são organizadas pelo número reduzido de alunos para cada série, por isso reúne numa mesma sala alunos com idade e níveis diferentes de escolarização, o que a caracteriza como mais do que uma simples classe. Ela representa um tipo de escola que é oferecida à determinada população e remete 
diretamente a uma reflexão sobre a concepção de educação com que se pretende trabalhar (ROSA, 2008). Neste sentido, Santos et al. (2010, p. 5) afirmam que,

O não reconhecimento das características da multisseriação (diversidade) nega as reais condições de trabalho e pode gerar uma série de problemas na prática docente. No entanto, as classes multisseriadas apresentam não só diferenças, mas também semelhanças. Há diferenças quando se consideram as séries, as idades, o sexo, os sonhos, as expectativas, as condições financeiras, socioculturais etc. As semelhanças ocorrem pelo desejo dos alunos de terem acesso a uma educação com boa qualidade de ensino; acesso aos meios de comunicação e conhecimentos; pelos direitos e deveres civis.

Reconhecer a importância das salas e escolas multisseriadas no processo de escolarização, e por que não, no processo de educação das populações campesinas é fundamental atualmente. Trata-se de se contrapor a uma perspectiva pejorativa e discriminatória que atribui a essa realidade um ensino concebido como provisório ou arremedo da educação seriada e urbana (JESUS; FOERSTE, 2018). Neste sentido, as salas multisseriadas têm sido uma alternativa para não afastar as crianças de sua realidade. Assim, a formação escolar adequada às condições das crianças do campo é um fator importante para a formação da autoestima e satisfação de sua condição cultural, social e econômica (MANTOVANELLI, 2013).

Infelizmente, nota-se que é meta nacional nuclear escolas, instituir a seriação como transformação e avanço, sem maiores reflexões sobre o que significa para uma comunidade do campo fechar uma escola, colocar suas crianças no transporte e levá-las para a cidade ou comunidades e bairros maiores. Ou ainda, sem refletir o que o fechamento de uma escola significa para a conjuntura social e econômica como um todo, para as relações entre campo e cidade, para a expulsão do camponês de sua terra. Afinal, as crianças que estão na escola não têm culpa do sistema capitalista ter expulsado as pessoas/os camponeses do campo. Nesse sentido, fechar uma escola do campo é fechar um espaço de convivência e de aprendizagens específicas, pois,

Quando falamos em nucleação temos que considerar que a cada escola constituída em núcleo correspondem várias escolas fechadas ou desativadas. O dramático é que a cada escola 
fechada é uma comunidade que se dilui ou até mesmo que se acaba. A existência de uma escola na comunidade movimenta as pessoas, provoca discussões, debates, reuniões e festas dando vitalidade ao espaço ocupado (MANTOVANELLI, 2013, p. 88).

Ao longo da história, criou-se um estigma de que nas classes multisseriadas o ensino não é bom, sendo de pouca qualidade voltando a atenção e dando preferência ao ensino da cidade que, mesmo sendo salas unisseriadas, não consideram a diversidade que nelas existem (MANTOVANELLI, 2013).

Arroyo (2006, p.115) diz que é necessário superar

[...] a reação tão frequente contra as escolas multisseriadas. As escolas do campo não são multisseriadas. São multiidades. Que é o diferente! Os educandos estão em múltiplas idades. Múltiplas temporalidades. Temporalidades éticas, cognitivas, culturais, identitárias. É com diversidade de temporalidades que trabalha a escola do campo.

Nesse sentido, Gauthier (2001), afirma que dentro da sala de aula os alunos formam uma espécie de micro sociedade, onde cada aluno vai se ajustando para a realidade do outro, aos poucos vão trocando informações, conhecimentos, experiências, assim, eles vão aprendendo uns com os outros, de uma forma espontânea.

Arroyo (2004, p. 169) nos fala que,

Não é o mesmo processar informação do que compreender significados. Os educandos não processarão informação sem aprender significados. Estes somente se aprendem na interação com os semelhantes, com humanos, com seu universo simbólico, com sua cultura.

Por isso, é importante que haja escolas onde as pessoas estão, vivem e trabalham. Geralmente nas classes multisseriadas, as crianças ajudam-se sem reclamar, naturalmente. Isso são posturas que não se aprendem na teoria, mas na prática do dia a dia, na convivência. Carvalho (2000, p. 16) nos fala que a escola tem um papel central no desenvolvimento das atitudes de cooperação, pois,

[...] Ela tem em suas mãos a oportunidade de ensinar o que é mais importante para os alunos: adquirir habilidades e aptidões 
que serão úteis para a vida e para o mercado de trabalho. A escola precisa ensinar cooperação. E a melhor maneira de fazêlo é através de modelos de trabalho em cooperação dentro da sala de aula.

Na sala multisseriada, os estudantes também aprendem com os colegas, ou seja, aprendem uns com os outros, enquanto trabalhamos com os alunos mais avançados os outros vão adquirindo outras aprendizagens e sendo motivados a discutir os vários saberes que surgem nas práticas cotidianas da sala de aula. Além disso, segundo Mantovanelli (2013, p. 113),

A importância do ensino nas salas multisseriadas vem reforçar a Educação do Campo como um instrumento importante no sentido de estar valorizando a cultura e a organização local a partir dos diversos olhares e lugares onde ela acontece.

Neste sentido, não podemos abandonar as classes multisseriadas e adotar o regime seriado, o qual promove a competição, o individualismo, a fragmentação de conhecimentos, podendo levar a desarticulação com a cultura, com os saberes dos camponeses. Deste modo, pensar em uma Escola do Campo,

[...] significa pensar e fazer a escola desde o projeto educativo dos sujeitos do campo, tendo cuidado de não projetar para ela o que sua materialidade própria não permite; trazer para dentro da escola as matrizes pedagógicas ligadas às práticas sociais; combinar estudos com trabalho, com cultura, com organização coletiva, com postura de transformar o mundo (CALDART, 2004, p. 35).

Neste sentido,

Entende-se por escolas do campo aquela que trabalha desde os interesses, a política, a cultura e a economia dos diversos grupos de trabalhadores e trabalhadoras do campo, na sua dimensão de permanente processo, produzindo valores, conhecimentos tecnologias na perspectiva do desenvolvimento social e econômico igualitário dessa população (KOLLING; NÉRY; MOLINA, 1999, p. 63).

Nessa concepção, é preciso compreender que uma escola do campo não precisa ser uma escola agrícola, mas será, necessariamente, uma escola vinculada à cultura que se produz por meio de relações sociais mediadas pelo trabalho na terra e não aquela que procura alimentar a falácia de que apenas a 
Educação do Campo, por si só, pode evitar o êxodo rural (KOLLING; NÉRY; MOLINA, 1999).

Nessa perspectiva, compreendemos que a partir da história encontramos pistas que nos desafiam a produzir outros discursos acerca da escola multisseriada. Uma escola que considera a realidade de vida dos sujeitos que dela fazem parte, que considera os saberes tradicionais da realidade na qual está inserida.

\section{Prática pedagógica em classe multisseriada envolvendo a produção oral e escrita a partir do plano de estudo}

Nas classes multisseriadas do campo as produções orais e escritas vão sendo desenvolvidas a partir da realidade dos estudantes, através de relatos orais, rodas de conversa, planos de estudo, produções textuais individuais e coletivas e dentre outros momentos.

É importante destacar que o Plano de estudo é um elemento pedagógico fundamental de interação entre teoria e prática, que direciona o trabalho curricular nas escolas multisseriadas do campo, de acordo com Nosella (2013, p. 208),

[...] O plano de Estudo é um guia (questionário) elaborado pelos alunos juntamente com a equipe dos professores, ao findar uma semana de aula, a fim de investigar, com seus pais, um aspecto da realidade cotidiana da família, seu meio e suas vivências. As respostas ao Plano de Estudo, que o aluno anota em seu caderno propriedade ou do lar, são postas em comum ao voltar à escola no inicio da sessão de aula (NOSELLA, 2013, p. 208).

Neste sentido, o Plano de estudo é desenvolvido a partir de um tema e é composto por perguntas que buscam investigar a realidade, para a partir dessa pesquisa aprofundar os conhecimentos científicos elucidando a realidade em que se inserem.

Considerando que a falta de água vem sendo um problema frequente na escola e na comunidade em que a pesquisa se realizou, e que mesmo após dialogarmos sobre a situação ainda não encontrávamos respostas, pensamos na proposta do plano de estudo com o tema Água a fim de elucidar a problemática observada. Neste sentido, elaboramos junto as crianças um 
questionário com perguntas feitas a partir das dúvidas e curiosidades das crianças relacionadas a problemática da água na comunidade. Essa atividade consistiu em realizar uma pesquisa no meio familiar, através de um questionário sobre o tema água, em que as crianças pesquisaram alguns dados em sua realidade a fim de compreender a crise hídrica na sua comunidade. A Figura 1 apresenta as perguntas que compõem o Plano de Estudo.

Figura 1 - Plano de Estudo/Ficha de pesquisa

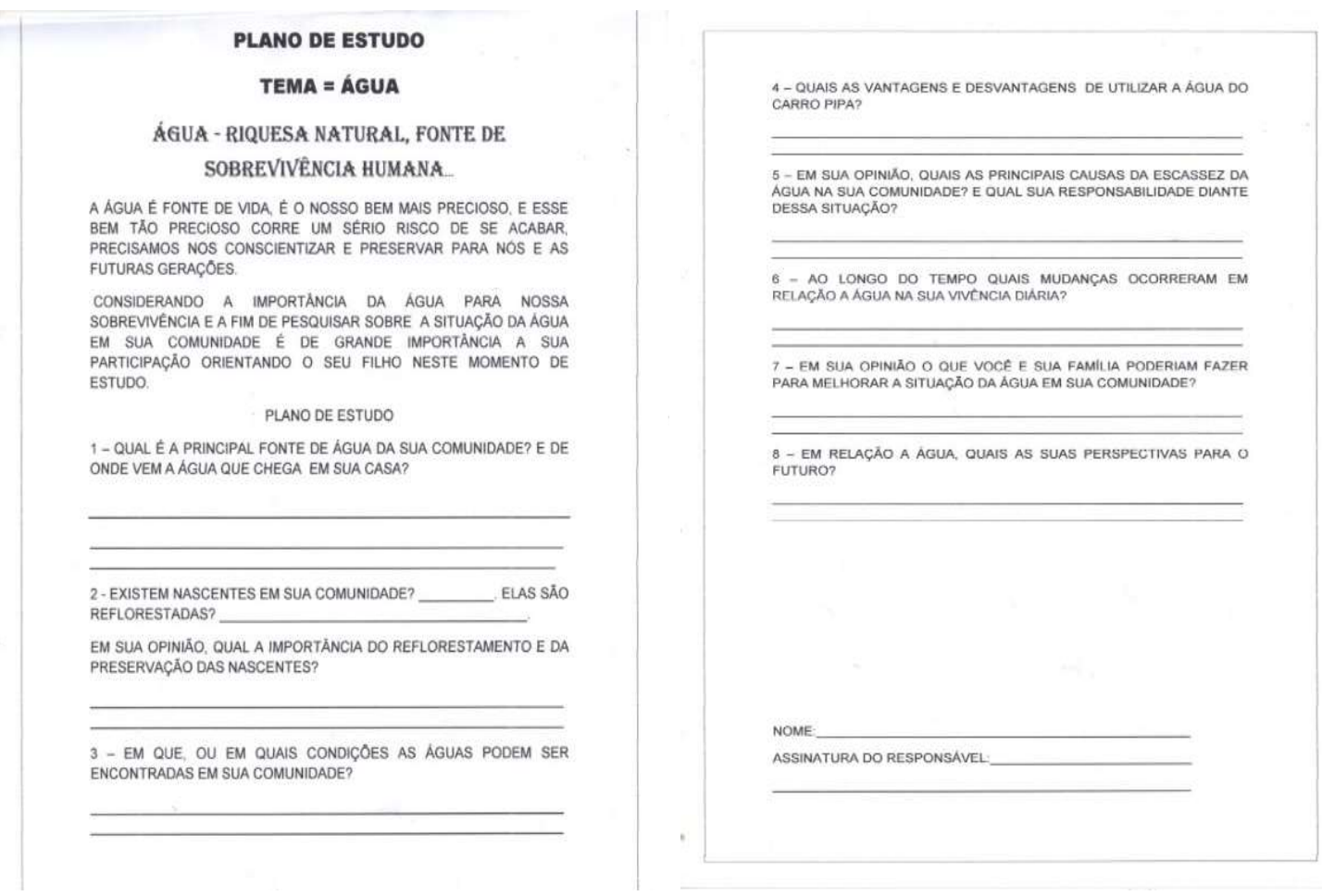

Fonte: A autora (2018)

As crianças levaram o Plano de Estudo/questionário para buscarem as respostas em seu meio familiar e comunitário, assim entrevistaram os seus familiares sobre o tema a ser pesquisado. Com as perguntas respondidas as crianças retornaram com o Plano de estudo para a escola. Neste momento que a criança retorna com o plano de estudo é feito uma roda de conversa, colocação em comum da pesquisa realizada no meio familiar. Depois que cada criança socializa a sua resposta, o professor reúne as perguntas e as repostas do plano de estudo dos estudantes e organiza um texto coletivo na lousa com a participação de todos os educandos. Este texto coletivo é chamado de síntese coletiva do plano de estudo. 
No momento de realização da síntese para a produção textual coletiva, a professora enquanto mediadora fazia as perguntas que estavam no plano de estudo, lia a pergunta e indagava sobre a resposta que estava no questionário de cada estudante, as crianças que ainda não liam, respondiam através da fala, argumentando acerca do que tinham ouvido dos pais ou responsáveis, ou realizavam a leitura com o auxílio da professora. Os estudantes que já sabiam ler, liam as respostas de cada pergunta e também argumentavam através da fala, pergunta por pergunta, a professora sempre questionava algo mais, a fim de compreender melhor a realidade e também para que as informações ficassem claras para todos. É importante destacar que no decorrer da produção textual sempre retornávamos ao início do texto, para observar se o mesmo estava ficando coerente e de fácil compreensão para todos os educandos da turma.

A produção textual coletiva visa dar voz a todos os estudantes, até mesmo os menores e mais tímidos, inclusive os da Educação infantil. Enquanto escrevia as palavras e frases ditas pelas crianças na lousa, sempre os indagava acerca da maneira correta para escrever as palavras na tentativa de certificar quais estudantes já dominavam o sistema alfabético da escrita, inclusive nas palavras com sílabas complexas, e quando as crianças apresentavam dúvida na escrita de determinada palavra, sempre fazia questão de esclarecer, por exemplo, nas palavras com ss, rr, ç, ch, s com som de z e dentre outras, assim muitas dúvidas eram sanadas coletivamente. Haja vista que segundo Smolka (1989, p. 61),

A construção do conhecimento sobre a escrita (na escola e fora dela) se processa no jogo das representações sociais, das trocas simbólicas, dos interesses circunstanciais e políticos; é permeada pelos usos, pelas funções e pelas experiências sociais de linguagem e interação verbal. Nesse processo o papel do outro como constitutivo do conhecimento é da maior relevância e significado (o que o outro me diz ou deixa de me dizer é constitutivo do meu conhecimento).

Neste sentido, a alfabetização precisa ser compreendida enquanto um processo de relações e trocas sociais, a escrita também é um processo de construção, por isso, é preciso ensinar às crianças as convenções da escrita, juntamente com os sentidos que se produzem ao escrever, pois a criação e a 
imaginação precisam ser alimentadas, assim, a mediação e a intervenção são fatores fundamentais nesse processo.

As crianças precisam compreender desde cedo que a escrita representa os sons da fala e é um recurso para recuperar a memória. Suas marcas gráficas representam significado para recordar algo, assim a escrita é desenvolvida em um processo de mediação, interação e nesse processo os alunos aprendem a escrever e a dizer suas compreensões pela escrita num processo de constantes sentidos atribuídos às marcas sob o papel.

Devido à complexidade da escrita e das várias maneiras de se compor um texto, o texto coletivo geralmente é mais demorado para se elaborar, mas ao mesmo tempo produz resultados significativos. É importante dar voz às crianças, e valorizar o seu discurso, por mais que pareça simples e incoerente para o texto que está sendo produzido, é relevante reorganizar a fala das crianças de modo que elas percebam as falas, as ideias ditas por elas presentes no texto, é claro que é preciso organizar essas falas de modo que o texto fique coerente e também acessível aos interlocutores, mas sem perder a essência do que as crianças disseram.

Outro ponto importante é manter a concentração das crianças no objetivo proposto, pois quanto maior a concentração e esforço dos estudantes em participar da produção, mais resultados positivos ela terá. É possível observar que as crianças do $1^{\circ}$ e $2^{\circ}$ ano permanecem concentradas por mais tempo e também conseguem elaborar as suas falas por meio de frases maiores, enquanto as crianças da educação infantil falam poucas palavras ou frases curtas e também se dispersam no decorrer da produção com mais facilidade, o que acaba dificultando a concentração por mais tempo. Nesse contexto, cabe ao professor lidar com esses condicionantes que surgem nas classes multisseriadas, fazendo as intervenções pedagógicas e retomando o objetivo proposto sempre que necessário.

Com relação à produção do texto coletivo, no início foi bem trabalhoso para começar a organizar as ideias, as falas de cada criança. Mas, aos poucos o texto foi rendendo, as lembranças foram surgindo, as crianças foram falando enquanto eu ia escrevendo na lousa, às vezes estava incoerente, precisava 
apagar, mas retomava o que a criança tinha falado, reorganizava a frase e escrevia na lousa novamente, depois líamos de novo e perguntava o que elas achavam, "e agora ficou melhor?".

Em alguns momentos, todas pareciam querer falar ao mesmo tempo, por isso, sempre lembrava da importância de falarmos um de cada vez e de ouvirmos uns aos outros, assim, o texto foi fluindo, chegou um momento em que precisei explicar que era necessário resumir/sintetizar um pouco as ideias para que o texto não ficasse muito extenso, em alguns momentos elas mencionavam o nome de algumas pessoas e me perguntavam porque eu não escrevia o nome da pessoa na lousa, então, expliquei que eu escrevia a informação, mas não escrevia o nome da pessoa para preservar a sua identidade, felizmente elas compreenderam e acharam importante.

Durante o diálogo, as crianças relataram que no decorrer da pesquisa com a família elas conseguiram perceber vários aspectos da sua realidade, o que acabou enriquecendo o nosso diálogo, pois a partir dos dizeres das crianças fomos organizando as ideias e produzindo o texto coletivo no quadro, de início algumas falas soltas que pareciam não fazer muito sentido na produção do texto, foram sendo organizadas com a minha mediação para a compreensão das escritas produzidas.

Neste sentido, a produção textual da síntese coletiva contribuiu no processo de escrita, organização textual e leitura, pois sempre retornávamos no início do texto fazendo a leitura coletiva em voz alta, além de possibilitar a compreensão das percepções dos estudantes sobre determinado assunto. Ao finalizar da produção textual, lemos novamente para ver se estava coerente e com todas as informações necessárias e fazer as últimas correções para darmos o ponto final em nosso texto. Assim, percebemos a alegria, entusiasmo e orgulho das crianças pela produção realizada.

Este momento foi de qualidade, as crianças perceberam suas falas contidas na produção tendo em vista os objetivos que permearam a elaboração da escrita. Assim, o processo de construção e escrita do texto foi produtivo e não um processo desagradável, mecânico e repetitivo, pois diferente de ser um momento árduo e doloroso, a escrita mediada pelo adulto foi enriquecedora no 


\section{processo de interação e alfabetização das crianças. A Figura 2 apresenta o texto coletivo produzido pela turma como resultado dessa atividade.}

Figura 2 - Produção de síntese coletiva do plano de estudo com o tema água ${ }^{2}$

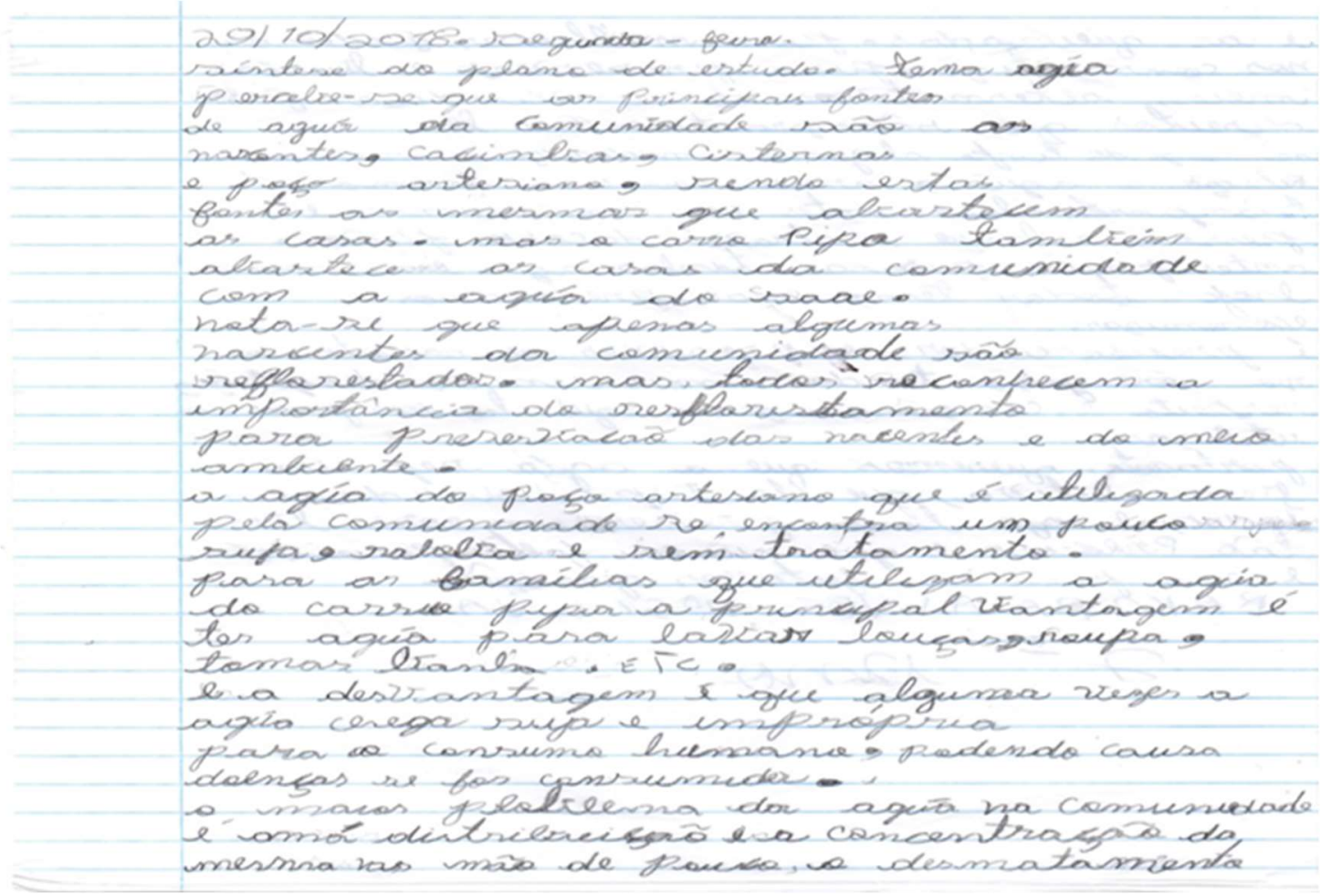

2 Síntese do plano de estudo. Tema: Água

Percebe-se que as principais fontes de água da comunidade são as nascentes, cacimbas, cisterna e poço artesiano, sendo estas fontes as mesmas que abastecem as casas. Mas o carro pipa também abastece algumas casas da comunidade com a água do SAAE.

Nota-se que apenas algumas nascentes da comunidade são reflorestadas, mas todos reconhecem a importância do reflorestamento para preservação das nascentes e do meio ambiente.

A água do poço artesiano que é utilizada pela comunidade se encontra um pouco suja, salobra e sem tratamento. Para as famílias que utilizam a água do carro pipa a principal vantagem é ter água para lavar louças, roupas, tomar banho, etc. A desvantagem é que algumas vezes a água chega suja e imprópria para o consumo humano, podendo causar doenças se for consumida.

O maior problema da água na comunidade é a má distribuição e a concentração da mesma nas mãos de poucos, o desmatamento e as queimadas. Para melhorar podemos nos conscientizar para preservar e buscar meios alternativos de reivindicar pelos direitos que são garantidos por lei.

Ao longo do tempo algumas mudanças ocorreram em relação à água, assim como, a forma de transportá-la, antes era as pessoas que conduziam os animais com uma carroça para buscar água e hoje é através do carro pipa, antes poucas pessoas tinham água encanada em casa, hoje todos têm, mas precisamos economizar, pois está em falta.

É preciso cuidar e preservar as nascentes, os rios e córregos, tendo mais união, diálogo, respeito e consciência para que todos possam utilizar.

Portanto, queremos que a água seja um bem coletivo, que ela seja dividida com todos, que todos preservem esse bem tão precioso e que nunca falte para nós e nem para as futuras gerações. 


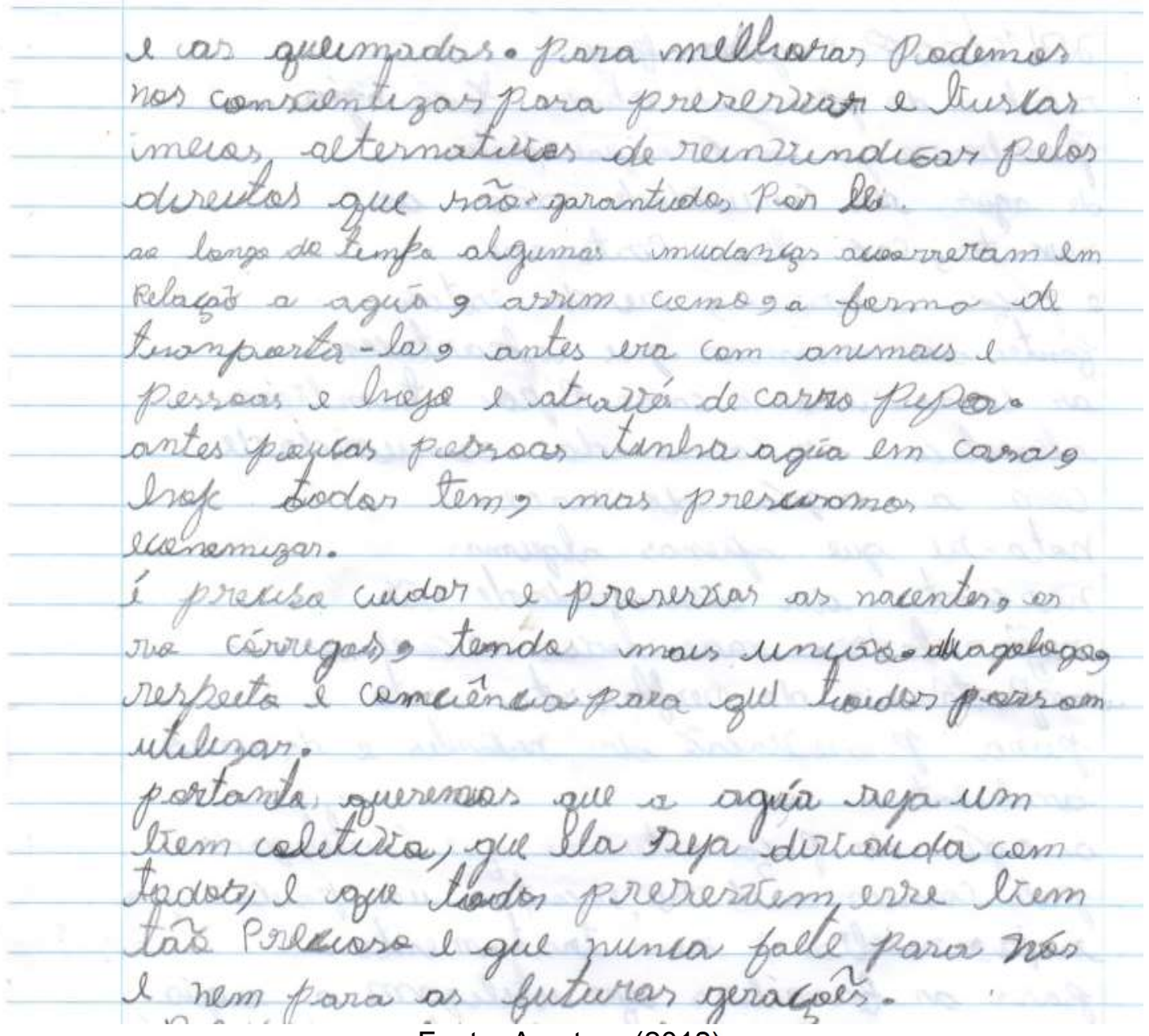
Fonte: A autora (2018)

A partir da roda de conversa/colocação em comum e da produção textual/síntese coletiva do plano de estudo, podemos inferir que na comunidade ainda há algumas fontes naturais de água, mas muitas delas se perderam por causa do desmatamento, e que a água do poço artesiano que abastece as casas da comunidade não é distribuída com equidade. No decorrer do diálogo, percebemos que os donos das terras ocupadas pelos latifúndios e minifúndios não se preocupam com a conservação dos recursos naturais, e que para essa matriz de racionalidade a natureza é instrumentalizada, mercantilizada, ou seja, o meio ambiente é tido como um recurso ou até mesmo como uma empresa para gerar fonte de renda e lucro. Neste sentido, Quintas (2004, p.116) afirma que, 
Há que se considerar, ainda, que o modo de perceber determinado problema ambiental, ou mesmo a aceitação de sua existência, não é meramente uma função cognitiva. A percepção dos diferentes sujeitos é mediada por interesses econômicos, políticos, posição ideológica, e ocorre num determinado contexto social, político, espacial e temporal.

Neste sentido, o plano de estudo por intermédio da pesquisa na realidade possibilitou compreender que a comunidade enfrenta uma situação séria de distribuição de água para consumo, há vários anos, evidenciando que a problemática da água também é causada pela má distribuição e organização, envolvendo relações de poder, pois os bens naturais vêm sendo transformados em recursos naturais. Por isso, Porto-Gonçalves (2006), afirma que,

O fundamento da relação da sociedade com a natureza sob o capitalismo está baseada na separação, a mais radical possível, entre os homens e mulheres, de um lado, e a natureza, de outro. A generalização do instituto da propriedade privada, ao privar a maior parte dos homens e das mulheres do acesso aos recursos naturais, cumpre um papel fundamental na constituição do capitalismo (PORTO-GONÇALVES, 2006, p.288).

Percebe-se que há um conflito entre formas diferenciadas de uso da natureza. Assim, parte da comunidade é abastecida pelo carro pipa que traz água da cidade de São Mateus. Um grande problema também é que o carro pipa nem sempre abastece as casas $\mathrm{e}$, isso provoca uma situação constrangedora $\mathrm{e}$ desumana aos moradores. Na comunidade também não possui saneamento básico, os dejetos são descartados em fossas que são cavadas no quintal de casa e o lixo na maioria das vezes é queimado, prejudicando o meio ambiente e a saúde dos moradores.

Neste sentido, não nos cabe reproduzir o discurso ideológico de que apenas fechar a torneira, desligar o chuveiro resolve os problemas ambientais do planeta, diminui a escassez da água, que na verdade em muitas situações não é escassez e sim má distribuição e concentração da mesma nas mãos de poucos. Por isso, a Educação Ambiental busca conscientizar, emancipar, transformar e promover a cidadania crítica, buscando romper com as demandas dominadoras da sociedade capitalista, pois, 
Não parece ser possível transformar a relação humano/natureza sem transformar simultaneamente as relações sociais, porque as dinâmicas entre as esferas social e natural estão articuladas na mesma conjuntura societária (LOUREIRO, 2012, p. 19).

A aplicação do plano de estudo enquanto elemento pedagógico nas práticas de ensino pode, por exemplo, explorar as razões dos conflitos pelo acesso e pelo uso dos recursos naturais que antagonizam interesses privados e públicos e a responsabilidade diferenciada dos diversos agentes sociais na produção da degradação ambiental.

Lima (2003), afirma que a ideia de aprendizado, assim considerada, adquire uma importância central na relação entre a educação, a emancipação e a sustentabilidade. O tipo de vida, de educação e de sociedade que teremos no futuro vai depender da qualidade, da profundidade e da abrangência dos processos de aprendizagem que formos capazes de criar e exercitar individual e socialmente. A educação e os educadores, em especial, que concentram as tarefas de conceber e por em prática os modelos de ensino e aprendizagem sociais têm uma responsabilidade singular nesse processo.

\section{Considerações Finais}

Através da pesquisa realizada concluímos que o Plano de Estudo, enquanto elemento pedagógico, busca problematizar a realidade concreta dos estudantes, por meio da investigação da realidade, na qual os estudantes expressam os seus saberes prévios, bem como trazem as reflexões feitas na família. Diante disso, os educadores vão mediando, na escola, um processo de colocação em comum e síntese dessas realidades, a fim de, juntamente com os estudantes, elencar situações que necessitam de aprofundamento científico (ALMEIDA, 2018).

Por isso, o plano de estudo é de fundamental importância, visto que possibilita aos estudantes estudar as problemáticas da sua comunidade, da sua realidade, pois estudar os próprios problemas tem um significado único que possibilita ao estudante educar seu olhar e percepção para estudar outros problemas, em outras escalas, além de possibilitar uma prática pedagógica significativa e contextualizada, pois entendemos que as crianças podem 
aprender a ler e a escrever dialogando acerca dos problemas ambientais e sociais de sua comunidade. Haja vista que para que a alfabetização aconteça de forma efetiva, torna-se necessário trazer as palavras do cotidiano, trazer o contexto, o significado para dialogar com a vida dos educandos, ou seja, contextualizar a escrita para a criança, dar significado e sentido ao fazer pedagógico, criar memória linguística a partir da prática com o contexto de uso social da escrita. Pois segundo Smolka (1989, p. 69),

[...] a alfabetização não implica, obviamente, apenas a aprendizagem da escrita de letras, palavras e orações. Nem tampouco envolve apenas uma relação da criança com a escrita. A alfabetização implica desde a sua gênese, a construção do sentido.

A alfabetização, entendida assim, é um processo de construção de conhecimento, um processo de interação, portanto, deve ser um processo discursivo e dialógico, de modo a conceber o trabalho escolar e suas relações com a vida social.

Para Kleiman (2005), se considerarmos a prática social como um dos elementos estruturadores do trabalho escolar, o ensino da leitura e da produção textual pode ser ampliado, visando ao letramento dos alunos e à sua inserção plena nas práticas sociais letradas.

Nesse sentido, as práticas de letramento precisam considerar as situações em que as escritas são produzidas e os contextos de sua produção. Pois, a alfabetização não consiste apenas na aquisição da escrita, do código da escrita, mas também na ênfase da função social da leitura e da escrita.

Paulo Freire (1989) já nos dizia que a leitura de mundo precede a leitura da palavra, ou seja, não basta ter a leitura das palavras, é preciso ter a leitura de mundo para que as palavras ganhem vida e significado.

Portanto, é possível perceber que o plano de estudo possibilita práticas de alfabetização significativas e contextualizadas acompanhadas de práticas situadas de letramento, pois possibilita a alfabetização vinculada ao seu existir, proporcionando o desenvolvimento da oralidade, leituras e produções textuais concebendo a leitura e a escrita como uma prática discursiva, não apenas como um código a ser decodificado. 


\section{Referências}

ALMEIDA, Valdinei de. Possibilidades e limites da produção curricular: um estudo de caso em um Centro Familiar de Formação em Alternância (CEFFA) do Município de São Mateus - ES. Dissertação apresentada no Programa de Pós-Graduação em Ensino na Educação Básica da Universidade Federal do Espírito Santo. São Mateus, 2018. Disponível em: http://portais4.ufes.br/posgrad/teses/tese_12115_81\%20-

\%20VALDINEI\%20DE\%20ALMEIDA.pdf. Acesso em 14 de agosto de 2020.

ARROYO, Miguel Gonzalez. A Educação básica e o movimento social do campo. In: ARROYO, M. G.; CALDART, R. S.; MOLINA, M. C. (Orgs.). Por uma Educação do Campo. Petrópolis (RJ): Vozes, 2004.

ARROYO, Miguel González. Escola do campo e a pesquisa do campo: metas. In: MOLINA, Mônica Castagna (Org.). Educação do Campo e pesquisa: questões para reflexão. Brasília: Ministério do Desenvolvimento Agrário - MDA, 2006.

CALDART, Roseli Salete. Elementos para a construção do Projeto Político e Pedagógico da Educação do Campo. In: MOLINA, Mônica Castagna, JESUS, S.M.S.A (Orgs). Por Uma Educação do Campo: Contribuições para a Construção de um Projeto de Educação do Campo. Brasília, DF: Articulação Nacional "Por uma Educação do Campo", 2004.

CALDART, Roseli Salete. Por uma Educação do Campo: traços de uma identidade em construção. In: KOLLING, Edgar Jorge; CERIOLI, Paulo Ricardo; osfs; CALDART, Roseli Salete (Org.). Educação do Campo: Identidade e Políticas Públicas. Brasília, DF: Articulação Nacional por Uma Educação do Campo, 2002. Coleção Por Uma Educação do Campo, nº 4, p. 25-36.

CAMACHO, R. S. O Agronegócio Latifundiário versus a Agricultura Camponesa: a luta política e pedagógica do campesinato. XIX Encontro Nacional de Geografia Agrária, São Paulo, 2009, p. 1-34.

CARVALHO, F. V. Pedagogia da Cooperação: uma introdução à metodologia da aprendizagem cooperativa. Piracicaba: Imprensa Universitária Adventista, 2000.

FREIRE, Paulo. A importância do ato de ler: em três artigos que se completam. 23.ed. São Paulo: Autores Associados: Cortez, 1989.

GAUTHIER, C. Triângulo didático-pedagógico: o triângulo que pode ser visto como quadrado. Revista Educação nas Ciências. Ijuí: Unijuí, jan.-jul., 2001.

GIL, A.C. Métodos e técnicas de pesquisa social. São Paulo: Atlas, 2014.

JESUS; Janinha Gerke; FOERSTE; Erineu. Escolas Multisseriadas do Campo: Histórico, Currículo, Saberes e Práticas Docentes. Documento. In: Módulo I. Escola da Terra Capixaba. FOERSTE, E.; JESUS, J.G.; ANDRADE, P.G.R.; 
SANTOS, J.S. Apresentação do módulo I. Introdução a Educação do Campo. 2018. Disponível em: https://ava.extensao.ufes.br/. Acesso em: 27 abr. de 2019.

KLEIMAN, Ângela B. Preciso "ensinar" o letramento? Não basta ensinar a ler e a escrever? Linguagem e letramento em foco. Ministério da educação, 2005.

KOLLING, Edgar Jorge; NERY, Irmão; MOLINA, Mônica Castagna (Org.). Por uma educação básica do campo (Memória). Brasília: Universidade de Brasília, 1998.

KOLLING, Edgar Jorge; NERY, Irmão; MOLINA, Mônica Castagna (Org.). Por uma educação básica do campo. Brasília: Fundação Universidade de Brasília, 1999.

LIMA, Eloisa Aparecida Cerino Rosa. FERNANDES, Silvia Aparecida de Sousa. Educação do Campo como projeto de desenvolvimento e de vida para o campo. Revista NERA, vol. 21, n. 45, p. 50-71, dez. 2018.

LIMA, G. F. C. O Discurso da Sustentabilidade e suas Implicações para a Educação. Ambiente e Sociedade (Campinas), Campinas - SP, v. VI, n.2, p. 99119, 2003.

LOUREIRO, Carlos Frederico Bernardo. Trajetórias e fundamentos da educação ambiental. 4. ed. São Paulo: Cortez, 2012.

MANTOVANELLI, Sandra Maria. Educação do Campo: Uma experiência inovadora educativa em salas multisseriadas do PROVER - Programa de Valorização da Educação Rural - Jaguaré -ES - Brasil. Dissertação apresentada ao Curso de Mestrado em Ciências da Educação da Universidade Americana, 2013.

NOSELLA, Paolo. Origens da Pedagogia da Alternância. Brasília, DF, 2007. União Nacional das Escolas Famílias Agrícola do Brasil - UNEFAB. Originalmente apresentada como dissertação de mestrado, Pontifícia Universidade Católica de São Paulo, 2013.

PORTO-GONÇALVES, Carlos Walter. A Globalização da Natureza e a Natureza da Globalização. Rio de Janeiro: Civilização Brasileira, 2006.

QUINTAS, J.S. Educação no processo de gestão ambiental: uma proposta de educação ambiental transformadora e emancipatória. In: LAYRARGUES, P.P. (Org.) Identidades da educação ambiental brasileira. Brasília: MMA/DEA, 2004.

RACEFFAES. Plano de Curso do Ensino Fundamental. São Gabriel da Palha, 2010.

ROSA. A. C. S. da. Classes multisseriadas: desafios e possibilidades. 2008. Disponível em: https://www.metodista.br/revistas/revistasims/index.php/EL/article/viewFile/116/ 126. Acesso em 07 de abril de 2019. 
SANTOS, M.M.C.; FILHO, M.B.S.; SANTOS, V.M.C.; SOUZA, M.F.M.; RODRIGUES, F.C. Educação ambiental e o homem do campo: vivências a partir de classes multisseriadas. Anais XVI Encontro Nacional dos Geógrafos. Crise, práxis e autonomia: espaços de resistência e de esperanças. Espaço de Diálogos e Práticas. Realizado de 25 a 31 de julho de 2010. Porto Alegre - RS, 2010. ISBN 978-85-99907-02-3.

SCARABELI, V. A formação social brasileira e o agronegócio em Mato Grosso. 108 pgs. Trabalho de Conclusão de Curso apresentado a Escola de Serviço Social da Universidade Federal do Rio de Janeiro - UFRJ, Rio de Janeiro, 2014.

SMOLKA, Ana Luiza Bustamante. A criança na fase inicial da escrita: A alfabetização como processo discursivo. 2.ed. São Paulo: Cortez, 1989.

\section{Sobre as autoras}

\section{Suelem Cardoso Miranda Rodrigues}

suelemmiranda20@hotmail.com

Mestra em Ensino na Educação Básica (2020) pela Universidade Federal do Espírito Santo (UFES), campus Centro Universitário Norte do Espírito Santo (CEUNES). Professora da Educação Infantil e Anos Iniciais do Ensino Fundamental contratada pela Secretaria Municipal de Educação (SME) do município de São Mateus - Espírito Santo.

\section{Sandra Mara Santana Rocha}

rochasms@gmail.com

Doutora em Engenharia Química pela Universidade Federal de Uberlândia. Professora do Departamento de Tecnologia Industrial da Universidade Federal do Espírito Santo.

\section{Rita de Cassia Cristofoleti}

rita.cristofoleti@ufes.br

Doutora em Educação pela Universidade Estadual de Campinas. Professora do Departamento de Educação e Ciências Humanas Ceunes/Ufes. Professora do Programa de Pós-graduação em Ensino na Educação Básica PPGEEB/CEUNES/UFES. 